\title{
Detection of fault during power swing in test system interconnected with DG
}

\author{
Nor Zulaily Mohamad ${ }^{1}$, Ahmad Farid Abidin', Ismail Musirin ${ }^{3}$ \\ ${ }^{1}$ Department of Electrical Power Engineering, Universiti Tun Hussein Onn Malaysia, Malaysia \\ ${ }^{2,3}$ Centre of Electrical Power Engineering Studies, Universiti Teknologi MARA, Malaysia
}

\begin{tabular}{l} 
Article Info \\
\hline Article history: \\
Received Nov 11, 2018 \\
Revised Feb 21, 2019 \\
Accepted Mar 22, 2019 \\
\hline Keywords: \\
Distance protection \\
Distributed generation (DG) \\
Fault detection \\
Power swing \\
S-transform
\end{tabular}

\begin{abstract}
Distance relay is prone to mal-operate during power swing, thus most of modern distance relay design is equipped with power swing blocking scheme to block the operation during power swing and reset the blocking operation whenever a fault occurs during power swing. However, the detection of fault during power swing especially for high resistance fault possess a challenging task, therefore it may cause the unblocking function to vulnerable to operate. This paper presents the development of a detection scheme for detecting fault during power swing in test system interconnected with Distributed Generation (DG). In this study, the detection scheme is proposed based on STransform analysis on the distance relay input voltage signal. It is demonstrated that the proposed S-Transform detection based scheme can effectively detect various type of fault during power swing includes high resistance fault, as well as able to operate correctly even with the presence of DG in the test system.
\end{abstract}

Copyright () 2019 Institute of Advanced Engineering and Science. All rights reserved.

\section{Corresponding Author:}

Nor Zulaily Mohamad,

Department of Electrical Power Engineering,

Universiti Tun Hussein Onn Malaysia, Malaysia.

Email: zulaily@uthm.edu.my

\section{INTRODUCTION}

Power swing is defined as a large fluctuation of power flow between two areas of power system and it is often occurs after the systems recovered from disturbances such as sudden addition or removal of loads in transmission line, line switching, or generator disconnection [1]. These system disturbances will cause oscillation in machine rotor angles which consequently lead to power swing scenario [2]. When power swing happen, the voltage and current signals are fluctuated causing the apparent impedance measured by the distance relay enter the relay tripping zones which leads to an un wanted relay operation [3].

Many studies have shown that the unwanted relay operation due to power swing has led to cascading power outage or power blackout, and consequential can jeopardize the safety and security of the consumers in general [4]. In order to prevent undesirable distance relay tripping during power swing, power swing blocking function is employed in distance relay to provide robust protection scheme during power swing [5]. However, if a fault occurs during power swing, the blocking function should be released and a trip signal should be activated by the distance relay for fault clearing operation [6].

The conventional distance relay design use the method of measuring either negative sequence or zero sequence components of current to detect fault during power swing [7]. Unfortunately, the major drawback of this method has been identified as it could not work to detect symmetrical fault during power swing. In [8], the authors proposed a new fault detection technique based on negative sequence component of the current signal. However, the technique is only can be used for detecting fault in compensated lines [9].

Several schemes have been proposed over the years to detect symmetrical fault during power swing. Reference [10] presents a fast symmetrical fault detector for distance relay based on feature of the frequency 
component of the active power signal after fault inception. It is reported that this method can sensitively detect the symmetrical fault, but it does not consider the fault resistance [9].

A new fault detection technique based on auto-regression analysis on the three-phase instantaneous power signal is presented in [11]. The auto-regression analysis is considered as a special technique for regression analysis where it can be used for predicting signals [12]. It is reported that the technique can accurately identify all type of fault with various conditions and applicable for both with and without compensation lines. However, the auto-regression based techniques requires a lot of simulations, thus it might be consider as computationally inefficient [9].

In recent years, several research and algorithm based on signal processing techniques have been proposed for detecting and identifying fault during power swing. In [13], the authors focus on developing wavelet energy based function for symmetrical fault detection during power swing. However, the success of implementation of wavelet based technique is definitely depends on the sampling frequency and proper selection of wavelet coefficient as any inaccuracy in the selections might cause the technique fails to operate correctly. Instead of wavelet, another advanced signal processing techniques which is known as S-Transform has been widely applied in power transient analysis and feature extraction. In [14], the authors present a new technique that used S-Transform as a feature extraction tool for identifying respective features of fault and power swing. Unfortunately, this technique was unable to be used for detecting high resistance fault.

This paper presents the development of a detection scheme for detecting fault during power swing for test system interconnected with DG based on S-Transform analysis on the distance relay input voltage signal. The main objective of the detection scheme is to differentiate between high resistance fault and power swing. The background theories of S-Transform are firstly presented in this paper, followed by the derivation equation of S-Transform to extract the feature between fault and power swing. Further, the results of fault detection scheme are discussed based on simulation with IEEE 39 bus system. In addition, a case study for testing the performance of fault detection scheme with effect of DG connected to the grid is performed based on simulation with IEEE 39 bus system.

\section{S-TRANSFORM}

S-Transform was proposed by Stockwell and his co-workers in 1996, inheriting the advantage of Short Time Fourier Transform (STFT) and Continuous Wavelet Transform (CWT) [15]. The S-Transform provides an accurate time-frequency resolution domain by employing a moving and scalable localized Gaussian window [16]. The general S-Transform equation is given as,

$$
S(\tau, f)=\int_{-\infty}^{\infty} x(t) \frac{|f|}{\sqrt{2 \pi}} e^{-\frac{(\tau-t)^{2} f^{2}}{2}} e^{-j 2 \pi f t} d t
$$

where,

$\tau \quad$ : time of spectral localization.

$f \quad$ : Fourier frequency.

$g(t)$ : window function.

The S-Transform can be written as operations on the Fourier spectrum $X(f)$ of $x(t)$ as,

$$
S(\tau, f)=\int_{-\infty}^{\infty} X(\alpha+f) e^{-\frac{2 \pi^{2} \alpha^{2}}{f^{2}}} e^{j 2 \pi \alpha \tau} d \alpha
$$

From (2), the S-Transform of discrete time series is shown in the following equation by letting $\tau \rightarrow v T$, $\mathrm{f} \rightarrow n / N T, \alpha \rightarrow m / N T$,

$$
S\left[v T, \frac{n}{N T}\right]=\sum_{m=0}^{N-1} X\left[\frac{m+n}{N T}\right] e^{-\frac{2 \pi^{2} m^{2}}{n^{2}}} e^{j \frac{2 \pi m v}{N}}
$$

where,

$v \quad:$ discrete time index.

$m, n$ : discrete frequency index.

$T \quad$ : sampling interval.

$N \quad$ : total of sampling point. 
From (3), the general equation of discrete time series of S-Transform can be further simplified as,

$$
S\left[v T, \frac{n}{N T}\right]=\sum_{m=0}^{N-1} X\left[\frac{m+n}{N T}\right] e^{\rho\left(\frac{m^{2}}{n^{2}}\right)} e^{\mu\left(\frac{m v}{N}\right)}
$$

where, $\rho=-2 \pi^{2}$ and $\mu=j 2 \pi$.

S-Transform is an appropriate signal processing tool to be used for analyzing non-stationary signal such as power swing $[17,18]$. In this study, the simplified equation of discrete time series of S-Transform in (4) will be used for derivation of feature extraction for identifying features of fault during power swing. The derivation of feature extraction for developing fault detection scheme will be fully discussed in the next section.

\section{PROPOSED FAULT DETECTION SCHEME USING S-TRANSFORM IN DISTANCE RELAY OPERATION}

The proposed fault detection scheme is conceptually based on S-Transform analysis on the voltage signal measured at distance relay point. Under both of power swing condition and fault during power swing condition, the retrieved voltage signal is calculated and processed through the discrete time series of $\mathrm{S}$ Transform equation in (4). The output of S-Transform is a duplicate time-frequency matrix called S-matrix whose row vectors pertain the information on the frequency, while column vectors pertain the information on the time [19]. Each element of the S-matrix is a complex value. The amplitude of S-Transform output in its corresponding frequency and time can be obtained by calculating the absolute value of S-matrix using following equation,

$$
\mu=\left|S\left[v T, \frac{n}{N T}\right]\right|
$$

where $\mu$ represents the amplitude of S-matrix.

Let $I=1, \ldots, v$ denote the indexes of the rows of a matrix $\mu, J=1, \ldots$, n denote the indexes of the columns of a matrix $\mu$, and $a_{i j}$ denote the $i j$ element of a matrix $\mu$. Thus, a vector of column-minima for Smatrix can be further calculated using following equation,

$$
\beta_{j}=\min _{i \in I} a_{i j}, j=1, \ldots, n
$$

where $\beta$ represents the smallest value of each columns in the matrix of amplitude of S-matrix.

Further, the next step of the feature extraction is to compute the maximum value of the vector of column-minima of S-matrix obtained from (6). This maximum value, which is defined as variable $k$, will be then used for the criterion for detection of fault in the power system. In this proposed fault detection scheme, there will be two different of variable $k$, which is defined as $k_{r e f}$ and $k_{f}$; where $k_{r e f}$ can be defined as the maximum value in the elements of S-Transform output during power swing with no fault condition, whereas $k_{f}$ can be defined as the maximum value in the elements of S-Transform output during the event of fault occurrence. The computation of $k_{r e f}$ and $k_{f}$ are performed using following equations,

$$
\begin{aligned}
& k_{r e f}=\left.\max _{j \in J} \beta_{j}\right|_{\text {no fault }} \\
& k_{f}=\left.\max _{j \in J} \beta_{j}\right|_{\text {fault }}
\end{aligned}
$$

The proposed fault detection criterion is defined by ratio of $k_{f}$ to $k_{r e f}$ as written in following equation,

$$
\gamma=\frac{k_{f}}{k_{r e f}}
$$


The results of $\gamma$ obtained from calculation in (9) is used to identify the faults occurrence during power swing based on comparison with the restrained coefficient set at 1 ; where if the ratio is greater than 1 , it means a genuine fault is detected. The selection of restrained coefficient setting of 1 is made based on several testing attained from the simulations, where it is found that the logic is true for all simulated cases. Figure 1 shows the proposed relay algorithm for fault detection scheme incorporating the S-Transform.

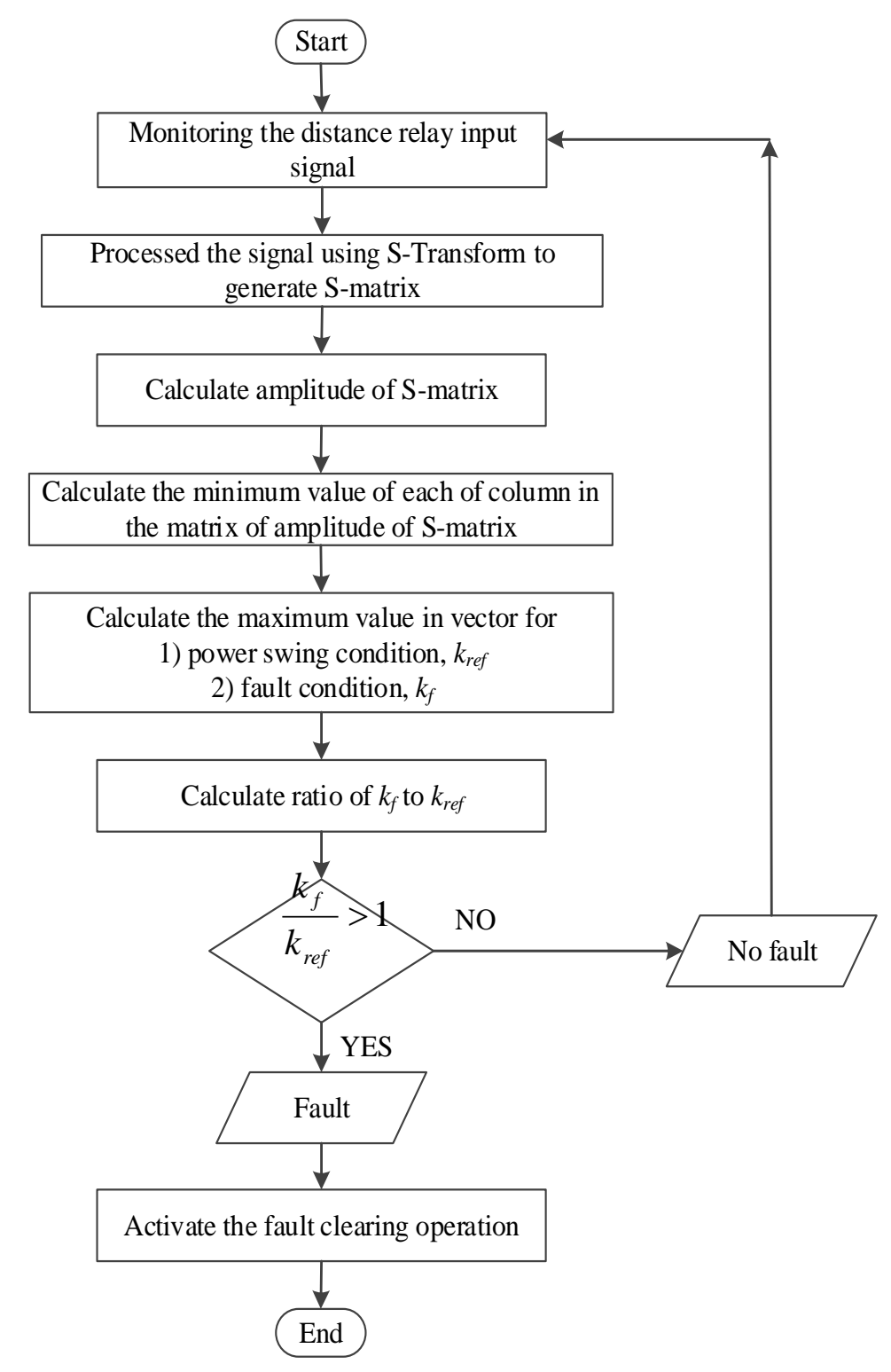

Figure 1. The proposed relay algorithm for detecting fault during power swing

\section{RESULTS AND ANALYSIS}

\subsection{Power swing simulation}

Power swing simulations need to be carried out before any further simulations can be made for the development of fault detection scheme. The power swing simulation models were developed using PSCAD $^{\text {TM}} /$ EMTDC $^{\text {TM }}$ software tool. Figure 2 shows the one-line diagram of IEEE 39 bus system that is used for simulation with power swing. The selected test system which is also known as 10-machine New England Power System consists of 10 generators and 17 loads; with total of generation and total of load capacity are 61.9293 MW and 50.373 MW, respectively [20]. 


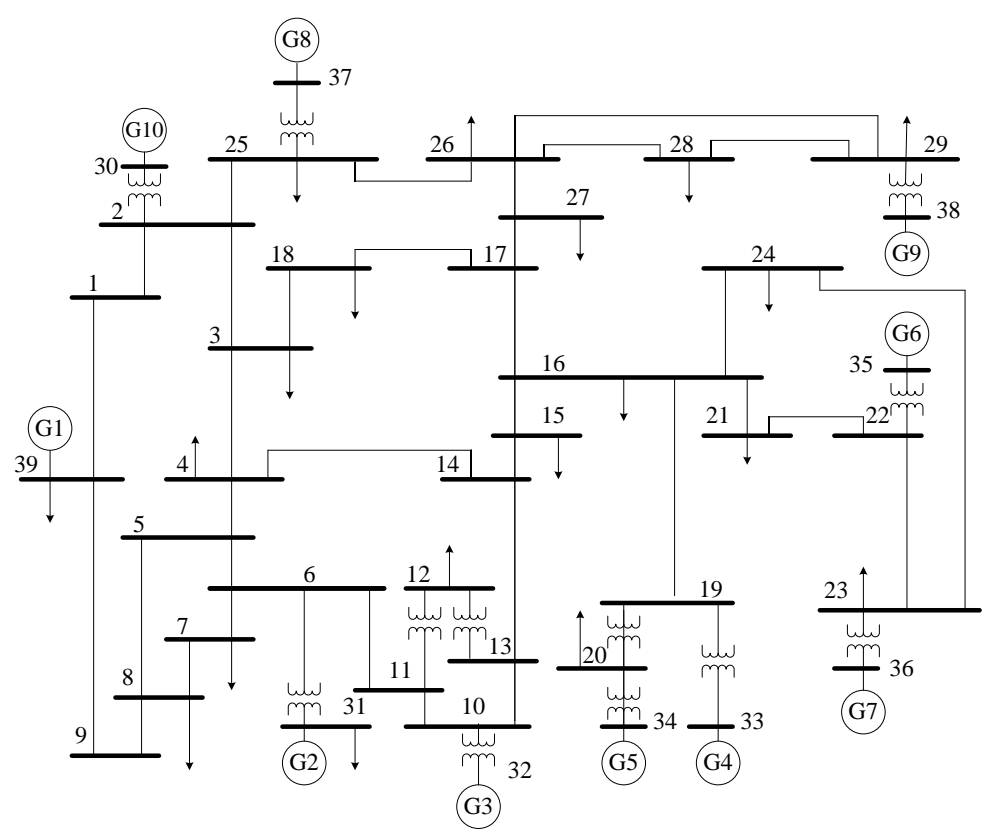

Figure 2. One-line diagram of the IEEE 39 Bus System used for power swing simulation

To perform the power swing simulation, a fault is set to be occurred in any branch of power network in the particular test system. Consequently, such disturbances will caused the system to experience the power swing condition. Further, since the proposed detection scheme is to detect the fault during power swing, another fault is set to be occurred while the test system is experiencing power swing.

Figure 3 shows the typical responses of voltage measured by the distance relay when a fault is set at $\mathrm{t}=1.0 \mathrm{~s}$ and cleared after $350 \mathrm{~ms}$. Consequently, such disturbance caused the post fault system experiences power swing. In Figure 4, another fault is occurred at $t=3.0 \mathrm{~s}$ while the system is experiencing the power swing.

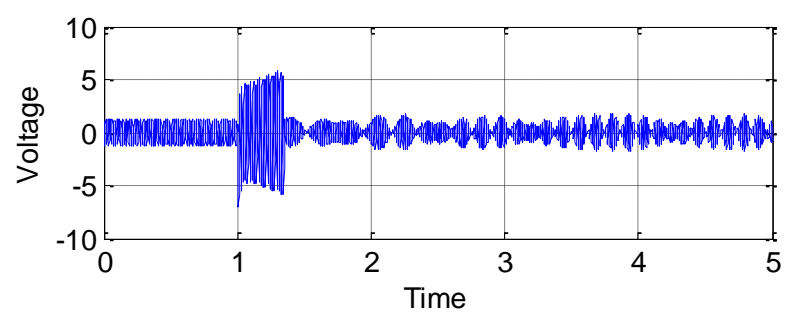

Figure 3. Typical responses of voltage in phase A during power swing

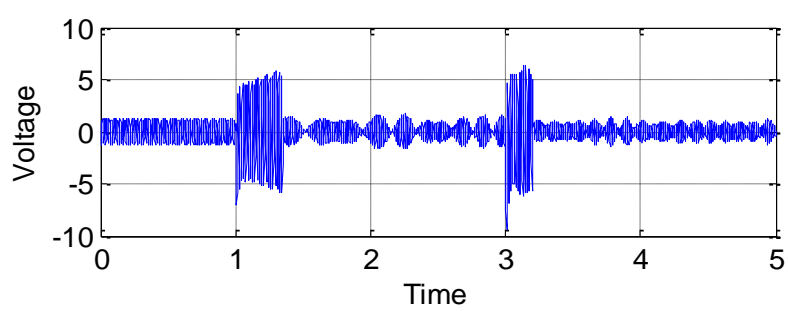

Figure 4. Typical responses of voltage in phase A during power swing and after three phase fault occurring at $\mathrm{t}=3.0 \mathrm{~s}$ 


\subsection{Testing of fault detection scheme on IEEE 39 bus system}

For implementation of the proposed scheme, several cases that considering various faults conditions are used to validate the performances of the proposed scheme. Table 1 represents various combination of fault conditions that have been used in this study. It is shown that the cases includes faults at different location in test system covering both of symmetrical faults $A B C-G$ and asymmetrical faults $A B$ types. In addition, the fault resistance is also varies from $10 \Omega$ up to $200 \Omega$.

Table 1. Test Conditions Adopted for Testing the Proposed Fault Detection Scheme Based on

\begin{tabular}{cccc}
\multicolumn{4}{c}{ IEEE 39 Bus System } \\
\hline Case & Fault Location & Fault Type & Fault Resistance $(\Omega)$ \\
\hline 1 & Line 16-17 & ABC-G & 10 \\
2 & & & 200 \\
3 & Line 3-18 & AB & 10 \\
4 & & & 200 \\
\hline
\end{tabular}

From the simulations of the above-mentioned cases, it is found that different fault location might affect different distance relay located at the adjacent faulty line [21]. Table 2 shows the location of affected distance relay for each of case studies that have been listed in Table 1 .

Table 2. Location of the affected distance relay for each of case studies based on IEEE 39 bus system

\begin{tabular}{cccc}
\hline Case & Fault Location & Adjacent Line & Location of Relay \\
\hline $1 \& 2$ & Line 16-17 & Line 17-18 & Bus 18 \\
& & Line 17-27 & Bus 27 \\
& & Line 16-19 & Bus 19 \\
& & Line 16-21 & Bus 21 \\
$3 \& 4$ & Line 3-18 & Line 3-4 & Bus 4 \\
& & Line 3-2 & Bus 2 \\
& & Line 18-17 & Bus 17 \\
\hline
\end{tabular}

Table 3 shows the performances of the proposed scheme based on simulations on IEEE 39 bus system. The results of $\gamma$ for the affected relays for each of case studies are computed and tabulated in Table 3 . It is shown in Table 3 that the value of $\gamma$ is greater than 1 for all cases. Thus, it is confirmed that the proposed scheme is able to sense the fault occurrence regardless any kind of fault type, fault location or fault resistance.

Table 3. The results of $\gamma$ for various case studies on IEEE 39 bus system

\begin{tabular}{cccc}
\hline Relay at Line & Fault Type & Fault Resistance $(\Omega)$ & $\gamma$ \\
\hline $17-18$ & ABC-G & 10 & 903.8 \\
& & 200 & 110.2 \\
$17-27$ & ABC-G & 10 & 649.7 \\
& & 200 & 63.8 \\
$16-19$ & ABC-G & 10 & 1085.1 \\
& & 200 & 28.6 \\
$16-21$ & ABC-G & 10 & 2561.6 \\
& & 200 & 23.6 \\
$3-4$ & AB & 10 & 1064.4 \\
& & 200 & 557.2 \\
$3-2$ & AB & 10 & 980.8 \\
& & 200 & 638.5 \\
$18-17$ & AB & 10 & 52.5 \\
& & 200 & 1.6 \\
\hline
\end{tabular}

\subsection{Testing of fault detection scheme on IEEE 39 bus system with Distributed Generation (DG)}

It is well known that the implementation of DG connected to the grid in the power system influences the operation of protection system performances [22]. Thus, it is crucial to ensure the proposed fault detection scheme is able to operate correctly even with the presence of DG in the grid. This section will discuss in details the performance of the proposed scheme for detecting fault during power swing with presence of DG based on simulation with IEEE 39 bus system. 
The DG source presented in this paper is modelled based on current source which has been successfully adopted in [23]. The placement of DG in the IEEE 39 bus system is considered to be located at the load bus which is remotely far end from the generators; which in this case referred to load bus 4 with load capacity of $500 \mathrm{MW}$ and 184 MVar. The size of DG is determined by $20 \%$ of the maximum feeder loading capacity at the selected load bus $[24,25]$.

After the placement and sizing of DG has been determined, the simulation testing to test the effectiveness of the proposed scheme on the IEEE 39 bus system connected with DG can be further simulated. In order to perform the testing, the same set of cases described in Table 1 will be repeated in this section.

Table 4 shows the performances of the proposed scheme based on simulation on IEEE 39 bus system connected with DG. From the simulations, the value of $\gamma$ for the affected relay for each of case studies are tabulated in Table 4. It is shown in Table 4 that the value of $\gamma$ is greater than 1 for all cases. Again, it can be concluded that the proposed scheme can significantly detect any type of fault during power swing even with presence of DG in the test system.

Table 4. The results of $\gamma$ for various case studies on IEEE 39 bus system connected with DG

\begin{tabular}{cccc}
\hline Relay at Line & Fault Type & Fault Resistance $(\Omega)$ & $\gamma$ \\
\hline $17-18$ & ABC-G & 10 & 52.6 \\
& & 200 & 11.2 \\
$17-27$ & ABC-G & 10 & 295.1 \\
& & 200 & 30.7 \\
$16-19$ & ABC-G & 10 & 90.2 \\
& & 200 & 27.3 \\
$16-21$ & ABC-G & 10 & 1666.4 \\
& & 200 & 80.9 \\
$3-4$ & AB & 10 & 100.5 \\
& & 200 & 10.1 \\
$3-2$ & AB & 10 & 1104.2 \\
& & 200 & 923.4 \\
$18-17$ & AB & 10 & 38.5 \\
& & 200 & 5.2 \\
\hline
\end{tabular}

\section{CONCLUSION}

This paper presents the development of a detection scheme for detecting fault during power swing for test system interconnected with DG. The proposed fault detection scheme based on S-Transform analysis have been presented in order to unblock the operation of distance relay when a fault occurs during power swing. The merit of the proposed scheme is proved by its ability to detect various type of fault regardless of its resistance level. In addition, the test results show the proposed scheme is able to detect all types of fault even with the presence of DG in the test system. Based on the analysis, it is proven that the proposed scheme which is based on S-Transform is very reliable to be applied in distance relay design due to its capability of identifying fault correctly.

\section{ACKNOWLEDGEMENTS}

The authors gratefully acknowledge the contribution of Registrar Office, Universiti Tun Hussein Onn Malaysia (UTHM) for the financial support of this research.

\section{REFERENCES}

[1] B. Taheri, et al., "Power Swing Detection Using the Variation Rates of the Average Value of Apparent Power," 2019 International Conference on Protection and Automation of Power System, pp. 38-43, 2019.

[2] D. Biswas, et al., "An artificial neural network based power swing classification technique," 2014 Annual IEEE India Conference, pp. 1-5, 2014.

[3] P. Sharma and R. N. Patel, "Mitigation and wavelet analysis for power swing in IEEE 9 bus system," $20163 r d$ International Conference on Advanced Computing and Communication Systems, pp. 1-5, 2016.

[4] C. L. Bak, et al., "Distance protection in $150 / 60 \mathrm{kV}$ transformer $60 \mathrm{kV}$ feeders: two real blackout case studies," The Journal of Engineering, vol. 2018, pp. 802-806, 2018.

[5] J. A. and D. S, "An Enhanced Symmetrical Fault Detection during Power Swing/Angular Instability using Park's Transformation," Indonesian Journal of Electrical Engineering and Computer Science, vol. 2, pp. 23-31, 2016.

[6] I. G. Tekdemir and B. Alboyaci, "A Novel Approach for Improvement of Power Swing Blocking and Deblocking Functions in Distance Relays,” IEEE Transactions on Power Delivery, vol. 32, pp. 1986-1994, 2017. 
[7] G. Benmouyal, et al., "Zero-setting power-swing blocking protection," 31st Annual Western Protective Relay Conference, pp. 19-21, 2004.

[8] S. Roy and P. S. Babu, "Power swing protection of series compensated transmission line with novel fault detection technique," 2014 International Conference on Green Computing Communication and Electrical Engineering, pp. $1-6,2014$.

[9] J. Khodaparast and M. Khederzadeh, "Three-phase fault detection during power swing by transient monitor," IEEE Transactions on Power Systems, vol. 30, pp. 2558-2565, 2015.

[10] B. Mahamedi and Z. J. Guo, "A novel approach to detect symmetrical faults occurring during power swings by using frequency components of instantaneous three-phase active power," IEEE Transactions on Power Delivery, vol. 27 , pp. 1368-1376, 2012.

[11] D. A. K. Rao, et al., "An autoregression-power based symmetrical fault detection during power swing," 2014 International Conference on Power Signals Control and Computations, pp. 1-5, 2014.

[12] K. Hua and D. A. Simovici, "Long-lead term precipitation forecasting by Hierarchical Clustering-based Bayesian Structural Vector Autoregression," 2016 IEEE 13th International Conference on Networking, Sensing, and Control, pp. 1-6, 2016.

[13] R. Dubey, et al., "Wavelet based energy function for symmetrical fault detection during power swing," 2012 Students Conference on Engineering and Systems, pp. 1-6, 2012.

[14] A. F. Abidin, et al., "Power swing detection for correct distance relay operation using S-transform and neural networks," 2011 5th International Power Engineering and Optimization Conference, pp. 279-284, 2011.

[15] Y. Yang, et al., "The Denosing of Seismic Signal Based on Generalized S Transform," 2014 Sixth International Conference on Intelligent Human-Machine Systems and Cybernetics, pp. 275-278, 2014.

[16] R. G. Stockwell, et al., "Localization of the complex spectrum: the S transform," IEEE Transactions on Signal Processing, vol. 44, pp. 998-1001, 1996.

[17] S. G. Tanyer, et al., "High Resolution Time-Frequency Analysis of Non-stationary Signals," $4^{\text {th }}$ International Conference on Control, Dynamic Systems, and Robotics, 2017.

[18] J. Long, et al., "Applications of fractional lower order S transform time frequency filtering algorithm to machine fault diagnosis," PloS one, vol. 12, 2017.

[19] L. Jiasheng, et al., "The Application Study of S-Transform Modulus Time-frequency Matrix in Detecting Power Quality Transient Disturbance," Information Technology Journal, vol. 11, pp. 354-358, 2012.

[20] P. Demetriou, et al., "Dynamic IEEE Test Systems for Transient Analysis," IEEE Systems Journal, vol. 11, pp. 2108-2117, 2017.

[21] S. Samira, et al., "Fault Resistance Effect on Distance Protection in High Voltage Transmission Lines," International Conference on Recent Advances in Electrical Systems, 2017.

[22] T. D. T. Nguyen, et al., "Study of Economical-Technical Impacts of Distributed Generation on Medium-Voltage Grid," TELKOMNIKA Indonesian Journal of Electrical Engineering, vol. 12, pp. 1177-1187, 2014.

[23] M. Sedghi and M. A. Golkar, "Analysis and Comparison of Load Flow Methods for Distribution Networks Considering Distributed Generation,” International Journal of Smart Electrical Engineering, vol. 1, pp. 27-32, 2012.

[24] K. Murari, "Optimal Sizing and Placement of DG in a Radial Distribution Network using Sensitivity based Methods," International Electrical Engineering Journal, vol. 6, 2015.

[25] T. Ramana, et al., "Distributed Generator Placement and Sizing in Unbalanced Radial Distribution System," Cogeneration \& Distributed Generation Journal, vol. 25, pp. 52-71, 2010.

\section{BIOGRAPHIES OF AUTHORS}

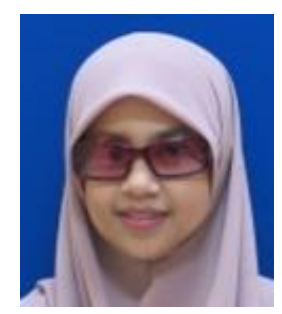

Dr. Nor Zulaily Mohamad was born in Malaysia, on October 7, 1985. She obtained Bachelor of Engineering in Electrical Engineering from Universiti Teknologi Malaysia in 2007 and Ph.D in Electrical Engineering from Universiti Teknologi MARA (UiTM), Malaysia in 2017. Her research interest includes power system protection and power quality. She is currently a lecturer at Faculty of Electrical and Electronic Engineering in Universiti Tun Hussein Onn Malaysia (UTHM), Malaysia.

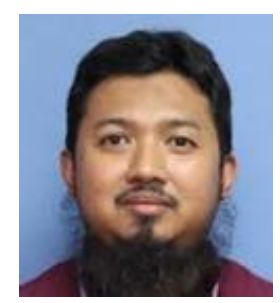

Assoc. Prof. Ir. Dr. Ahmad Farid Abidin was born in Malaysia, on Dec 25, 1978. He obtained Bachelor of Engineering in Electrical, Electronic, and System Engineering in 2000 from Universiti Kebangsaan Malaysia, M.Sc in Electrical Engineering in 2005 from Universiti Teknologi MARA (UiTM), Malaysia, and Ph.D in Electrical Engineering from Universiti Kebangsaan Malaysia in 2011. His main research interests are in power system stability, power quality and power system protection. He is currently a senior lecturer at the Faculty of Electrical Engineering, UiTM and the Director, Community of Research (CoRe), Advanced Computing and Communication (ACC), Institute of Research Management and Innovation, UiTM since Feb 2018. 
Prof. Ir. Dr. Ismail Musirin was born in Malaysia, on September 6, 1966. He obtained

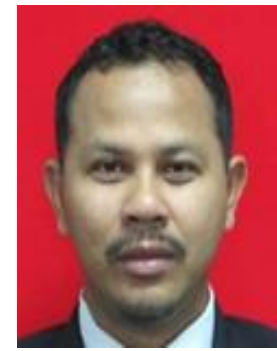

Bachelor of Electrical Engineering (Hons) in 1990 from Universiti Teknologi Malaysia, MSc

in Pulsed Power Technology in 1992 from University of Strathclyde, United Kingdom and

$\mathrm{PhD}$ in Electrical Engineering from Universiti Teknologi MARA (UiTM), Malaysia in 2005.

His research interest includes artificial intelligence, optimization techniques, power system analysis, renewable energy, distributed generation and power system stability. He is currently Professor of Power System at the Faculty of Electrical Engineering, UiTM. 